\title{
Stress relaxation and reversed flow of low-density polyethylene melts following uniaxial extension.
}

\author{
Huang, Qian; Rasmussen, Henrik K.; Skov, Anne Ladegaard; Hassager, Ole
}

Published in:

Journal of Rheology

Publication date:

2012

Document Version

Publisher's PDF, also known as Version of record

Link back to DTU Orbit

Citation (APA):

Huang, Q., Rasmussen, H. K., Skov, A. L., \& Hassager, O. (2012). Stress relaxation and reversed flow of lowdensity polyethylene melts following uniaxial extension. Journal of Rheology, 56(6), 1535-1554.

http://journalofrheology.org/resource/1/jorhd2/v56/i6/p1535_s1

\section{General rights}

Copyright and moral rights for the publications made accessible in the public portal are retained by the authors and/or other copyright owners and it is a condition of accessing publications that users recognise and abide by the legal requirements associated with these rights.

- Users may download and print one copy of any publication from the public portal for the purpose of private study or research.

- You may not further distribute the material or use it for any profit-making activity or commercial gain

- You may freely distribute the URL identifying the publication in the public portal

If you believe that this document breaches copyright please contact us providing details, and we will remove access to the work immediately and investigate your claim 


\title{
Stress relaxation and reversed flow of low-density polyethylene melts following uniaxial extension
}

\author{
Qian Huang \\ Department of Chemical and Biochemical Engineering, \\ Technical University of Denmark, DK-2800 Kgs. Lyngby, Denmark \\ Henrik K. Rasmussen \\ Department of Mechanical Engineering, Technical University of Denmark, \\ DK-2800 Kgs. Lyngby, Denmark \\ Anne L. Skov and Ole Hassager ${ }^{a)}$ \\ Department of Chemical and Biochemical Engineering, \\ Technical University of Denmark, DK-2800 Kgs. Lyngby, Denmark
}

(Received 21 February 2012; final revision received 29 August 2012; published 21 September 2012)

\begin{abstract}
Synopsis
The extensional dynamics of two low-density polyethylene melts Lupolen 3020D and Lupolen 1840D, both showing a stress overshoot in start-up of uniaxial extension [Rasmussen, H. K., J. K. Nielsen, A. Bach, and O. Hassager, "Viscosity overshoot in the start-up of uniaxial elongation of low density polyethylene melts," J. Rheol. 49(2), 369-381 (2005)], have been further investigated in stress relaxation and reversed flow. After the overshoot, the stress relaxation has a remarkably faster decrease of the transient stress than when the relaxation is initiated before the overshoot. The measurements from the reversed flow also show that the melts appear less elastic after the overshoot. Multi mode versions of the pom-pom and interchain pressure model fit the data quantitatively up to the stress maximum, but neither model captures the qualitative behavior after the maximum. (C) 2012 The Society of Rheology. [http://dx.doi.org/10.1122/1.4752759]
\end{abstract}

\section{INTRODUCTION}

Polymer fluids exhibit complex dynamics and rheology, which affect the processing and properties of the final products. The ability to predict and control the rheological behavior of polymer fluids as a function of molecular chemistry has attracted a long history of collaboration between industry and academia. Especially the extensional flow, which is the dominant type of deformation in many industrial polymer processes, still presents challenges both experimentally and theoretically in academia to capture and explain the stress-strain responses.

\footnotetext{
a) Author to whom correspondence should be addressed; electronic mail: oh@kt.dtu.dk
} 
Accurate and reliable stress-strain measurements of the extensional flow play a crucial role in the understanding of nonlinear rheological properties of polymers. During the last decades, different types of extensional rheometers have been developed, such as the rheometrics melt extensiometer (RME) [Meissner (1972); Meissner and Hostettler (1994)], the Münstedt tensile rheometer (MTR) [Münstedt (1979)], the Sentmanat extensional rheometer (SER) [Sentmanat (2004)], and the filament stretching rheometer (FSR) [McKinley and Sridhar (2002)]. The most frequently reported measurements using these extensional rheometers are either the steady or the transient stress in start-up of uniaxial extension. Measurements of stress relaxation with the SER [Sentmanat et al. (2005)] are limited to low Hencky strains due to the necking instability [Wang et al. (2007)]. Measurements of reversed flow have been reported for low-density polyethylene (LDPE) melts [Meissner (1971); Wagner and Stephenson (1979)] in the form of free recovery. This is a controlled stress experiment as opposed to the controlled strain experiment to be considered here. The recovered strains can therefore not be directly compared.

Recently new techniques to measure stress relaxation [Nielsen et al. (2008)] and reversed biaxial flow [Nielsen and Rasmussen (2008)] both following uniaxial extension, as well as large amplitude oscillatory extension (LAOE) [Bejenariu et al. (2010)], have been presented. These experiments were performed with an FSR modified for high-temperature measurements of polymer melts by Bach et al. (2003). With the aid of a closed loop controller, the filament diameter in the mid-plane is controlled accurately and therefore the extension rate can be controlled even during the necking phase [Wang et al. (2007); Lyhne et al. (2009)]. Work regarding stress relaxation and reversed flow using the FSR has been done on both linear [Nielsen et al. (2008); Nielsen and Rasmussen (2008)] and branched [Rasmussen et al. (2009)] narrow molar mass distribution (NMMD) polymer melts, but not yet on polydisperse melts. Measurements of NMMD polymer melts of known structures are important for the understanding of nonlinear flow properties. However, many commercially available polymers, such as LDPE, are branched and highly polydisperse. A maximum in the transient elongational stress coefficient of LDPE was observed by Raible et al. (1979) and modeled by Wagner et al. (1979) for the first time. Recently, Read et al. (2011) proposed a predictive scheme of the linear and nonlinear response for industrial polymers. They compared the nonlinear predictions with the measurements of uniaxial extension for three LDPE melts. However, the experimental data were limited below a Hencky strain of 3.5.

FSR measurements on LDPE melts have previously been reported by Bach et al. (2003) and Rasmussen et al. (2005). In the latter investigation, the samples were extended to a Hencky strain of 7 and a steady stress following the overshoot was reported. In order to investigate further the extensional dynamics of LDPE, especially the rheological behavior associated with the overshoot, we will present the measurements of stress relaxation and reversed biaxial flow both following the uniaxial extension on two commercial LDPEs.

\section{MATERIALS}

Two types of commercial LDPEs, Lupolen 3020D and Lupolen 1840D provided by BASF, have been chosen for this study. The Lupolen 3020D and 1840D LDPE melts have been previously characterized in shear by Bastian (2001) and by Rasmussen et al. (2005), respectively. Rasmussen et al. (2005) also measured the extensional stress growth coefficient in uniaxial elongation for both melts. The LDPE samples we used in this study are both from the same batches as in Rasmussen et al. (2005), and the elongation measurements are in agreement with Rasmussen et al. (2005) as well. 
The properties of the LDPE melts are listed in Table I. The Lupolen 1840D has much wider molar mass distribution. The molecular structure of the Lupolen 1840D, among other LDPE melts, has been discussed in Nordmaier et al. (1990a, 1990b). The linear viscoelastic spectrum for Lupolen 3020D from Bastian was originally given at $170{ }^{\circ} \mathrm{C}$. In Table I, we have shifted it to $130{ }^{\circ} \mathrm{C}$ with the time-temperature shift factor $a_{T}=6.4$ obtained from Rasmussen et al. (2005). The average relaxation time $\tau_{0}$ is defined as

$$
\tau_{0}=\frac{\sum_{i} g_{i} \tau_{i}^{2}}{\sum_{i} g_{i} \tau_{i}},
$$

where $g_{i}$ and $\tau_{i}$ are listed in Table I.

Both LDPEs were supplied in pellets and were hot pressed into cylindrical test samples at $130{ }^{\circ} \mathrm{C}$, with radius $R_{0}=4.5 \mathrm{~mm}$ and length $L_{0}=2.5 \mathrm{~mm}$, giving an aspect ratio $\Lambda_{0}=L_{0} / R_{0}=0.556$.

\section{FILAMENT STRETCHING RHEOMETRY}

The experiments are performed with an FSR equipped with an oven to allow measurements from room temperature to about $200{ }^{\circ} \mathrm{C}$ [Bach et al. (2003)]. Nitrogen is used during the elongation to avoid sample degradation. The force $F(t)$ is measured by a load cell and the diameter $2 R(t)$ at the mid-filament plane is measured by a laser micrometer. The Hencky strain and the mean value of the stress difference over the mid-filament plane [Szabo (1997)] are calculated from observations of $R(t)$ and $F(t)$ as

$$
\epsilon(t)=-2 \ln \left(R(t) / R_{0}\right)
$$

TABLE I. Properties of the Lupolen 3020D and Lupolen 1840D LDPE melts. Linear viscoelastic spectrum

\begin{tabular}{|c|c|c|c|c|}
\hline Polymer melt & \multicolumn{2}{|c|}{ LDPE } & \multicolumn{2}{|c|}{ LDPE } \\
\hline Product & \multicolumn{2}{|c|}{ Lupolen 3020D } & \multicolumn{2}{|c|}{ Lupolen 1840D } \\
\hline$M_{w}(\mathrm{~kg} / \mathrm{mol})$ & \multicolumn{2}{|c|}{300} & \multicolumn{2}{|c|}{490} \\
\hline$M_{n}(\mathrm{~kg} / \mathrm{mol})$ & \multicolumn{2}{|c|}{37.5} & \multicolumn{2}{|c|}{16} \\
\hline$M_{w} / M_{n}$ & \multicolumn{2}{|c|}{8} & \multicolumn{2}{|c|}{30.6} \\
\hline$T_{m}\left({ }^{\circ} \mathrm{C}\right)$ & \multicolumn{2}{|c|}{114} & \multicolumn{2}{|c|}{110} \\
\hline \multirow[t]{9}{*}{ Relaxation spectrum at $130^{\circ} \mathrm{C}$} & $\tau_{i}(\mathrm{~s})$ & $g_{i}(\mathrm{~s})$ & $\tau_{i}(\mathrm{~s})$ & $g_{i}(\mathrm{~s})$ \\
\hline & 0.009421 & 140281.5 & 0.0115 & 129000 \\
\hline & 0.061312 & 53547.1 & 0.107 & 43600 \\
\hline & 0.319808 & 33532.91 & 0.56 & 24200 \\
\hline & 1.8272 & 20196.16 & 3.35 & 12700 \\
\hline & 10.4064 & 9170.150 & 17.3 & 6200 \\
\hline & 57.9328 & 3551.614 & 95.5 & 2900 \\
\hline & 329.024 & 983.4258 & 823 & 831 \\
\hline & 2097.92 & 101.618 & & \\
\hline$\tau_{0}(\mathrm{~s})$ at $130^{\circ} \mathrm{C}$ & \multicolumn{2}{|c|}{636.612} & \multicolumn{2}{|c|}{523.117} \\
\hline
\end{tabular}
from Bastian (2001) for Lupolen 3020D $\left(130^{\circ} \mathrm{C}\right)$ and Rasmussen et al. (2005) for Lupolen $1840 \mathrm{D}\left(130^{\circ} \mathrm{C}\right)$. 
and

$$
\left\langle\sigma_{z z}-\sigma_{r r}\right\rangle=\frac{F(t)-m_{f} g / 2}{\pi R(t)^{2}},
$$

where $m_{f}$ is the weight of the filament and $g$ the gravitational acceleration. At small strains during the startup, part of the stress difference comes from the radial variation due to the shear components in the deformation field, especially at small aspect ratios. This effect may be compensated by a correction factor where the corrected mean value of the stress difference is defined as [Rasmussen et al. (2010)]

$$
\left\langle\sigma_{z z}-\sigma_{r r}\right\rangle_{c o r r}=\left\langle\sigma_{z z}-\sigma_{r r}\right\rangle\left(1+\frac{\exp \left(-5 \epsilon / 3-\Lambda_{0}^{3}\right)}{3 \Lambda_{0}^{2}}\right)^{-1}
$$

This relation ensures less than 3\% deviation from the correct initial stress. For large strains, the correction vanishes and the radial variation of the stress in the symmetry plane becomes negligible [Kolte et al. (1997)].

The strain rate is defined as $\dot{\epsilon}=d \epsilon / d t$. During the startup of uniaxial stretching, we define $\dot{\epsilon}_{0}^{+}=\dot{\epsilon}$ and in the reversed biaxial flow, we define $\dot{\epsilon}_{0}^{-}=-\dot{\epsilon}$, where $\dot{\epsilon}_{0}^{+}$and $\dot{\epsilon}_{0}^{-}$stay positive, constant, and equal. During the stress relaxation starting at an arbitrarily given Hencky strain of $\epsilon_{0}$, the mid-filament radius is kept constant by the active control loop, giving $\dot{\epsilon}=0$. The Weissenberg number is defined as $W i=\dot{\epsilon} \tau_{0}$.

The key feature of the FSR that allows us to control the strain rate is that the location of the thinnest part of the filament can be predicted. Provided a critical strain rate $\dot{\epsilon}_{s a g}=\rho g L_{0} / \eta_{0}$ is exceeded [McKinley and Sridhar (2002)], the thinnest part of the filament is expected to occur in the mid-plane. Therefore, the strain rate $\dot{\epsilon}_{s a g}$ gives a lower limit for the rates at which the FSR control scheme will work. To ensure that the FSR is working correctly, we therefore check that the test samples should stay symmetric across the mid-filament plane as well as axisymmetric during extension [Burghelea et al. (2011); Rasmussen and Hassager (2012)]. Figures 1-8 illustrate the samples controlled by the FSR in the measurements of stress relaxation and reversed flow.

In Fig. 1, the dark part shows the contour of the Lupolen 3020D filament from the laser monitor at different Hencky strain values during a uniaxial stretching. The flow was stopped at Hencky strain $\epsilon_{0}=4.5$ and followed by the stress relaxation. Figure 2 shows the corresponding Hencky strain as a function of time, including the other two measurements where the flow was stopped at $\epsilon_{0}=2$ and 3 , respectively.

Figure 3 shows the quenched Lupolen 3020D filament when the flow was stopped at Hencky strain $\epsilon_{0}=4.5$ and relaxed for $100 \mathrm{~s}$, while Fig. 4 shows the quenched Lupolen $1840 \mathrm{D}$ filament when the flow was stopped at $\epsilon_{0}=5.0$ and relaxed for $100 \mathrm{~s}$ as well. We

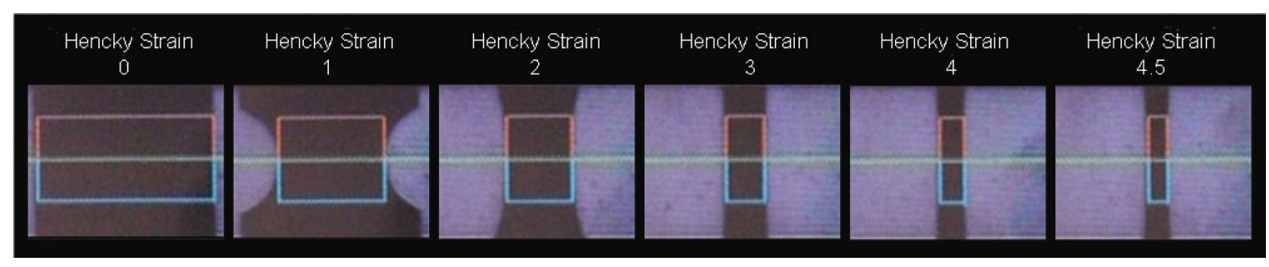

FIG. 1. Contour of the Lupolen 3020D filament at different Hencky strain values during a uniaxial stretching at $130^{\circ} \mathrm{C}$ with $\dot{\epsilon}_{0}^{+}=0.03 \mathrm{~s}^{-1}$. 


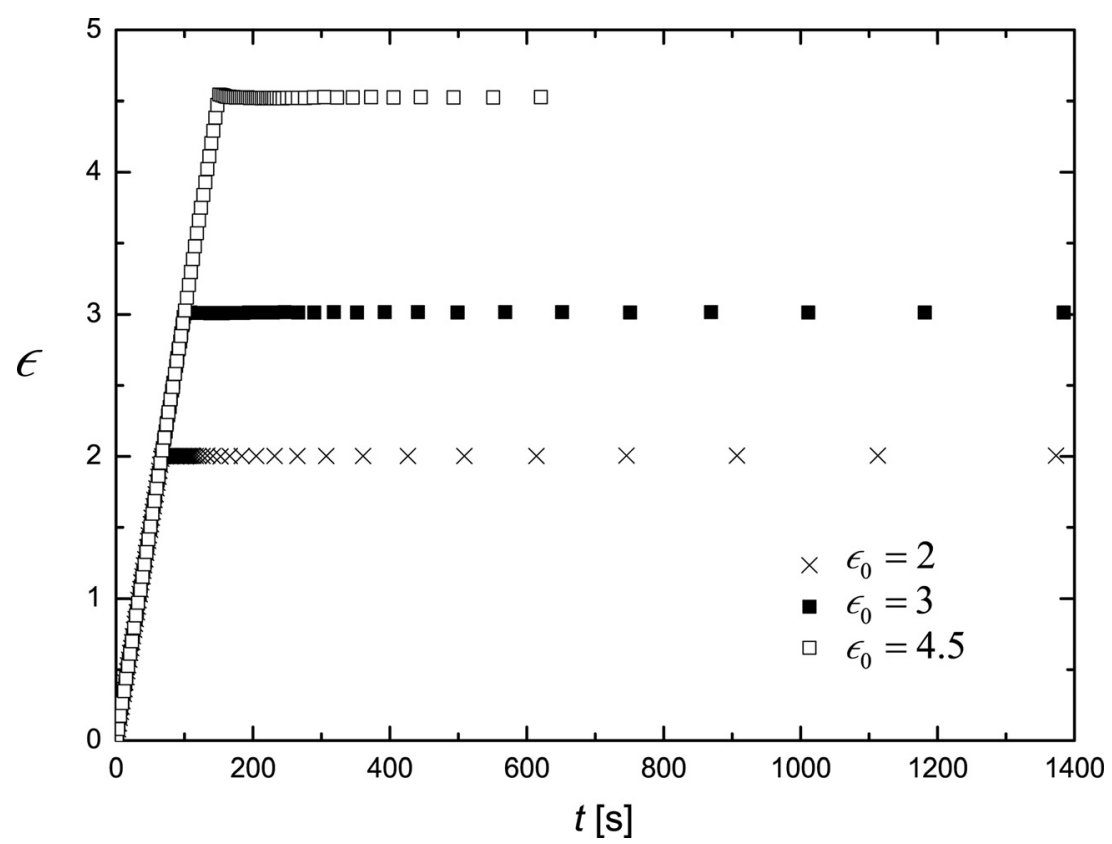

FIG. 2. Hencky strain $\epsilon$ of the Lupolen $3020 \mathrm{D}$ samples measured by the FSR at $130^{\circ} \mathrm{C}$ as a function of time $t$. The startup of the flow is uniaxial elongation with $\dot{\epsilon}_{0}^{+}=0.03 \mathrm{~s}^{-1}$; the flow was stopped at $\epsilon_{0}=2,3$, and 4.5, respectively.

quenched the filaments by opening the oven and exposing the samples to the atmosphere. The quenching process took around $15 \mathrm{~s}$. During this time, there was no control by the closed loop, thus $0.05-0.08 \mathrm{~mm}$ decreases of the mid-diameter of the quenched samples were observed. Figures 5 and 6 show the corresponding contours scanned by the laser

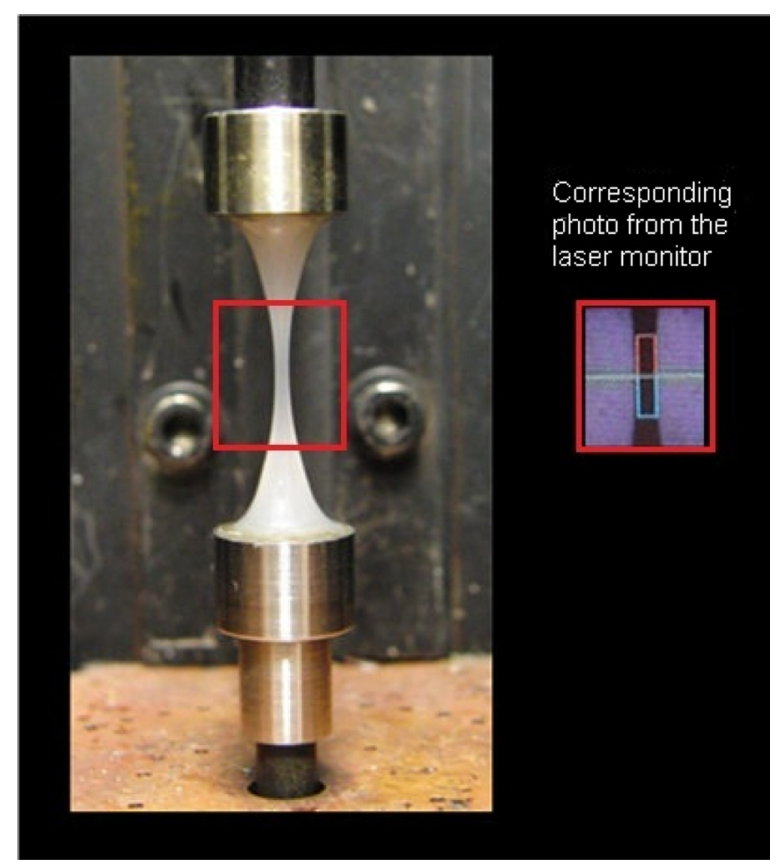

FIG. 3. Quenched Lupolen 3020D filament. The flow was stopped at $\epsilon_{0}=4.5\left(\dot{\epsilon}_{0}^{+}=0.03 \mathrm{~s}^{-1}\right)$ and relaxed for $100 \mathrm{~s}$. 


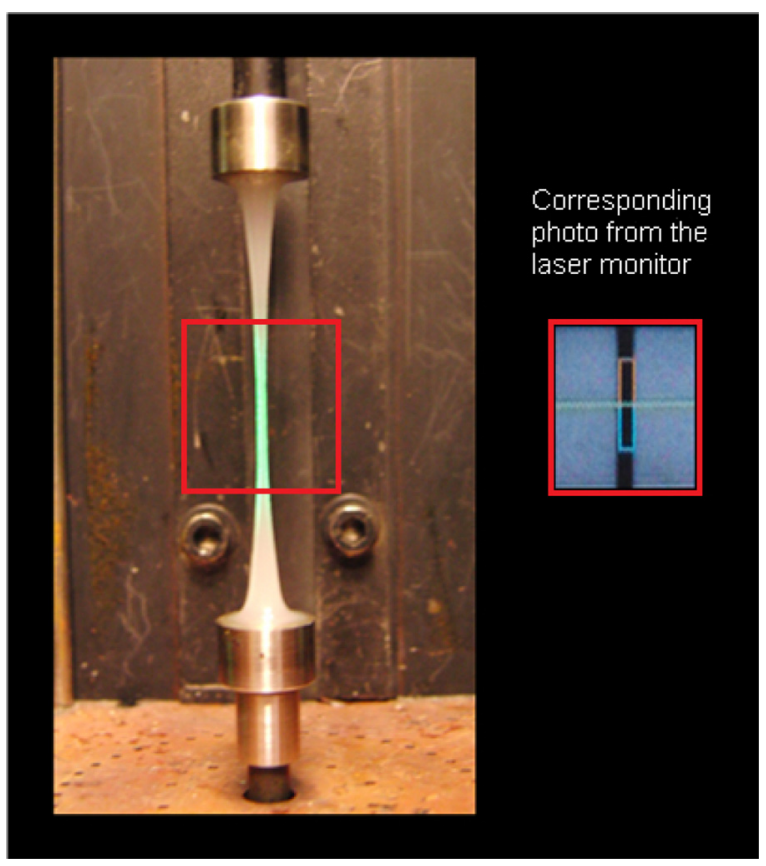

FIG. 4. Quenched Lupolen 1840D filament. The flow was stopped at $\epsilon_{0}=5.0\left(\dot{\epsilon}_{0}^{+}=0.01 \mathrm{~s}^{-1}\right)$ and relaxed for $100 \mathrm{~s}$.

micrometer of the same filaments in Figs. 3 and 4, respectively. Figures 3 and 4 depict the front side of the filaments, while Figs. 5 and 6 show the left side of the filaments. In Figs. 5 and 6, the position $Y=0$ indicates where the mid-plane of the filament is located. The quenched sample in Fig. 5 is almost perfectly symmetric across the mid-plane.

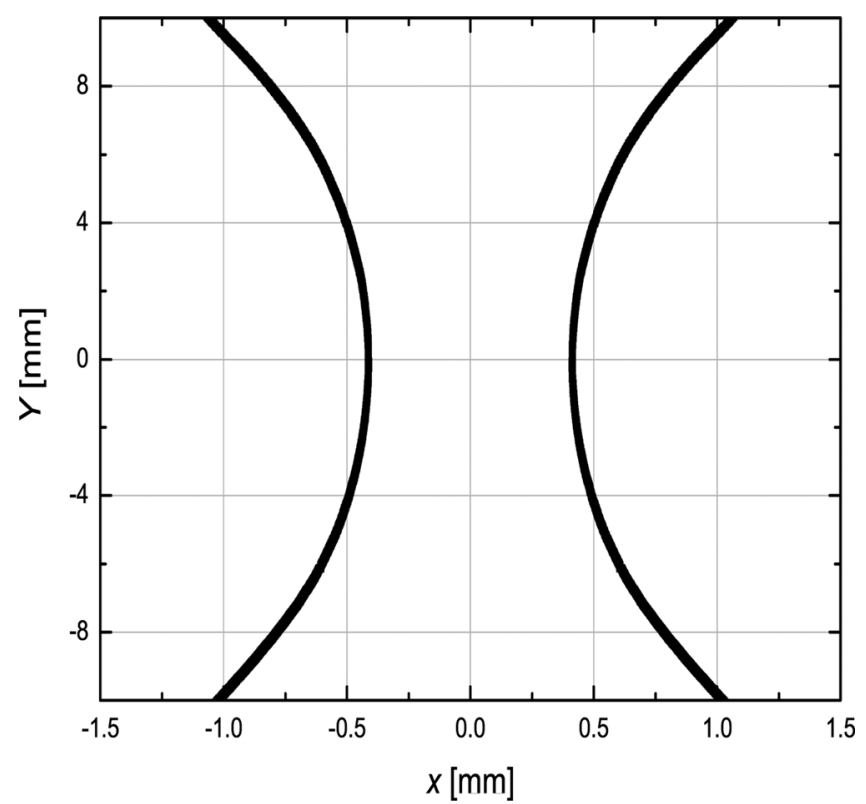

FIG. 5. Contour scanned by the laser micrometer of the quenched Lupolen $3020 \mathrm{D}$ filament delimited by the red square in Fig. 3. The flow was stopped at $\epsilon_{0}=4.5\left(\dot{\epsilon}_{0}^{+}=0.03 \mathrm{~s}^{-1}\right)$ and relaxed for $100 \mathrm{~s}$. 


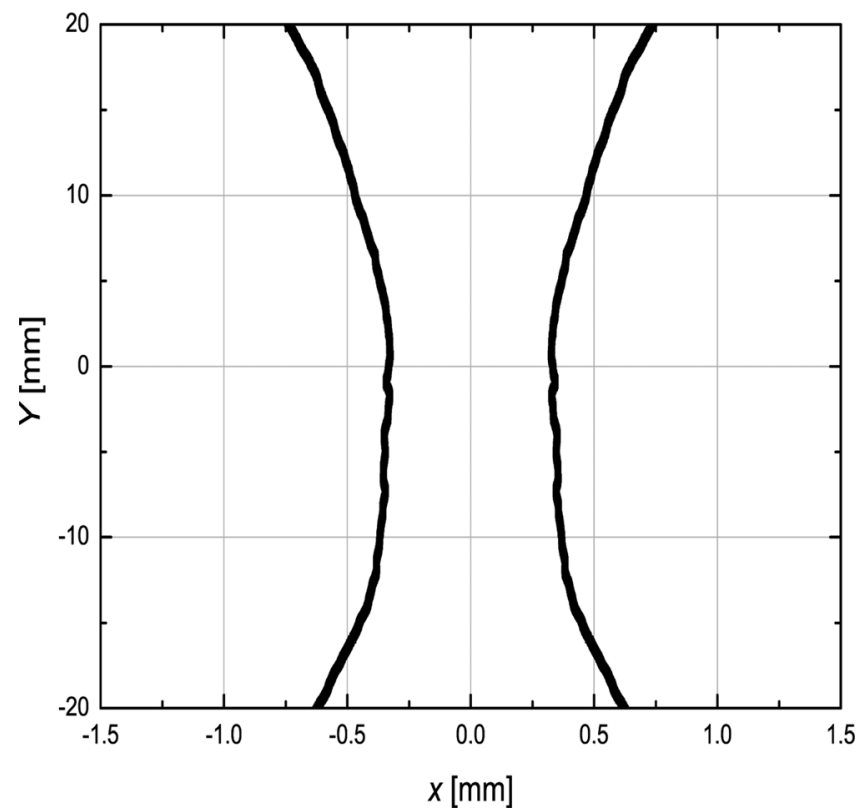

FIG. 6. Contour scanned by the laser micrometer of the quenched Lupolen $1840 \mathrm{D}$ filament delimited by the red square in Fig. 4. The flow was stopped at $\epsilon_{0}=5.0\left(\dot{\epsilon}_{0}^{+}=0.01 \mathrm{~s}^{-1}\right)$ and relaxed for $100 \mathrm{~s}$.

Figure 7 shows the contour of the Lupolen 1840D filament from the laser monitor at different Hencky strain values during a uniaxial stretching followed by a reversed biaxial flow. The flow was reversed at $\epsilon_{0}=4.5$. At some time $t_{R}$, the stress changes sign from positive to negative (tension to compression). The strain recovery is defined as $\epsilon_{R}=$ $\epsilon_{0}-\epsilon\left(t_{R}\right)$ [Nielsen and Rasmussen (2008)]. If the flow is continued for $t>t_{R}$, the filament will buckle at some time as shown in Fig. 7 (Hencky strain 3). Figure 8 shows the corresponding Hencky strain of Lupolen $1840 \mathrm{D}$ as a function of time, including the other five measurements, where the flow was reversed at different Hencky strains $\epsilon_{0}$ ranging

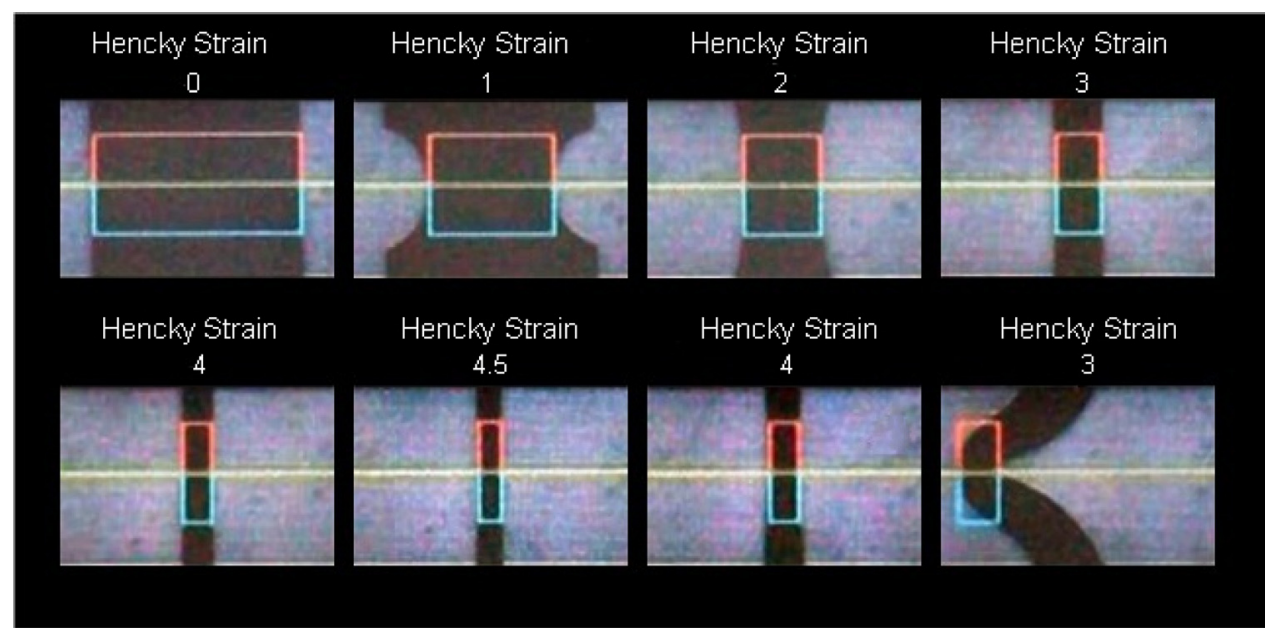

FIG. 7. Contour of the Lupolen 1840D filament at different Hencky strain values during a uniaxial stretching with $\dot{\epsilon}_{0}^{+}=0.01 \mathrm{~s}^{-1}$ followed by a reversed biaxial flow with $\dot{\epsilon}_{0}^{-}=0.01 \mathrm{~s}^{-1}$ at $130^{\circ} \mathrm{C}$. The flow was reversed at $\epsilon_{0}=4.5$. 


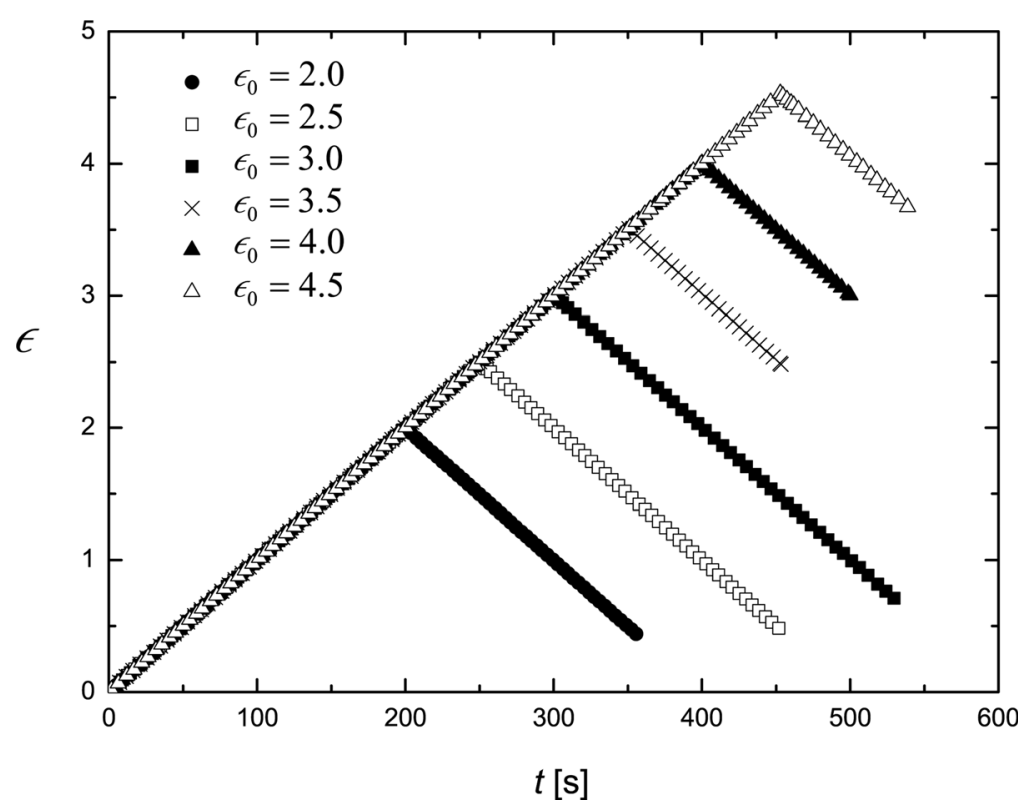

FIG. 8. Hencky strain $\epsilon$ of Lupolen $1840 \mathrm{D}$ samples measured by FSR at $130^{\circ} \mathrm{C}$ as a function of the time $t$. The startup of the flow was uniaxial elongation with $\dot{\epsilon}_{0}^{+}=0.01 \mathrm{~s}^{-1}$. The flow was reversed at $\epsilon_{0}=2.0,2.5,3.0,3.5,4.0$, and 4.5 , respectively, with the identical strain rate $\dot{\epsilon}_{0}^{-}=0.01 \mathrm{~s}^{-1}$.

from 2 to 4 . The figure contains kinematic data for some unbuckled filaments under compression. However, no force measurements are reported for filaments under compression.

\section{STRESS RELAXATION}

The experiments of stress relaxation were performed at $130^{\circ} \mathrm{C}$ following start-up of uniaxial elongation. The flow was stopped at different Hencky strains before and after the overshoot, and the stress was followed during the relaxation phase. Figures 9 and 10 show the experimental results of Lupolen 3020D and 1840D, respectively. In the figures, each measurement was repeated twice and the plots present the de-noised data after wavelet processing [Mallat (2009)]. In order to obtain a manageable data set, we picked one data point from every ten points in the data set after wavelet processing. We also analyzed the data by taking the average value of every ten data points in the original data set, which gave a good agreement with the wavelet analysis. Figure 11 compares the raw data and the data after wavelet processing. The raw data show the three measurements of Lupolen 1840D with $\dot{\epsilon}_{0}^{+}=0.01 \mathrm{~s}^{-1}$ and $\epsilon_{0}=4.5$. This raw data are the most scattering case among all the measurements.

The lines in Figs. 9 and 10 show the predicted results of the original reptation based model introduced by Doi and Edwards (1979). The stress tensor is expressed as

$$
\sigma(t)=\int_{-\infty}^{t} M\left(t-t^{\prime}\right) \mathbf{S}_{\mathrm{DE}}\left(t, t^{\prime}\right) \mathrm{d} t^{\prime}
$$

where $M\left(t-t^{\prime}\right)$ is the memory function with

$$
M\left(t-t^{\prime}\right)=\sum_{i} \frac{g_{i}}{\tau_{i}} e^{-\left(t-t^{\prime}\right) / \tau_{i}}
$$




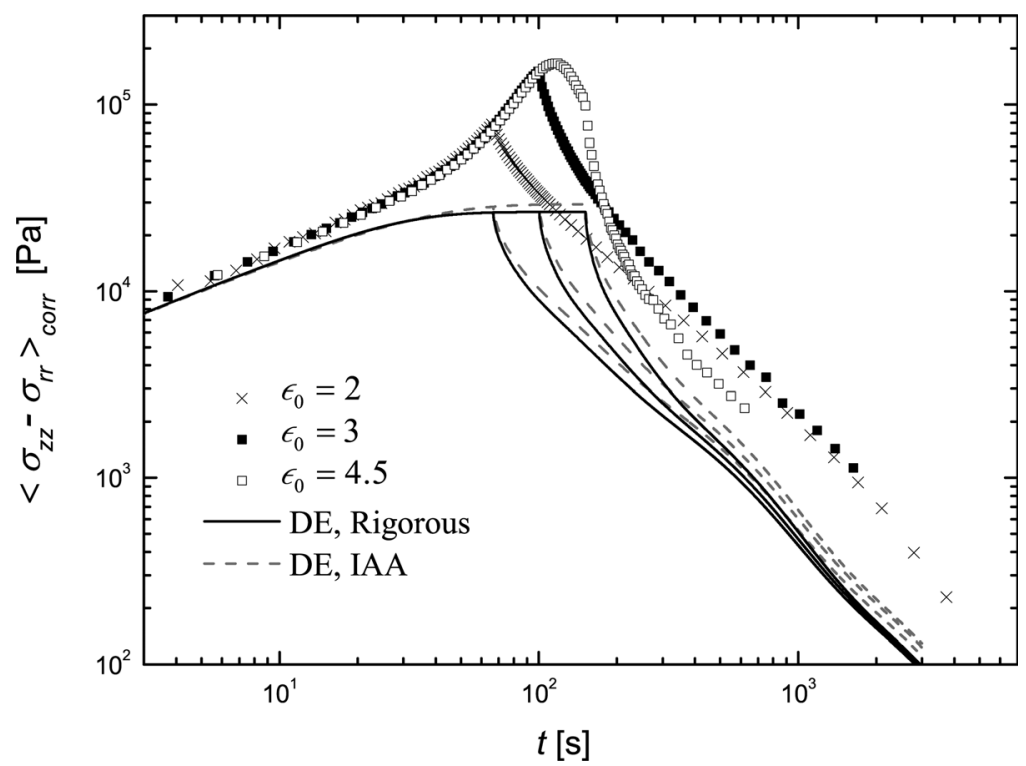

FIG. 9. The corrected extensional stress of Lupolen $3020 \mathrm{D}$ as a function of time at $130{ }^{\circ} \mathrm{C}$ with $\dot{\epsilon}_{0}^{+}=0.03 \mathrm{~s}^{-1}$ $(W i=19.1)$. The flow was stopped at an extension of $\epsilon_{0}=2,3$, and 4.5 , respectively. The dashed and solid lines are the corresponding DE predictions with and without IAA, respectively.

Inherently in the original Doi-Edwards (DE) model is a specific form of the linear viscoelastic memory function $M\left(t-t^{\prime}\right)$ developed for monodisperse linear polymers. This form will clearly not fit the linear viscoelastic properties of the highly branched and polydisperse LDPE melts. Hence we use the memory function corresponding to the experimentally determined relaxation function with parameters $g_{i}$ and $\tau_{i}$ in Table I. Thus when

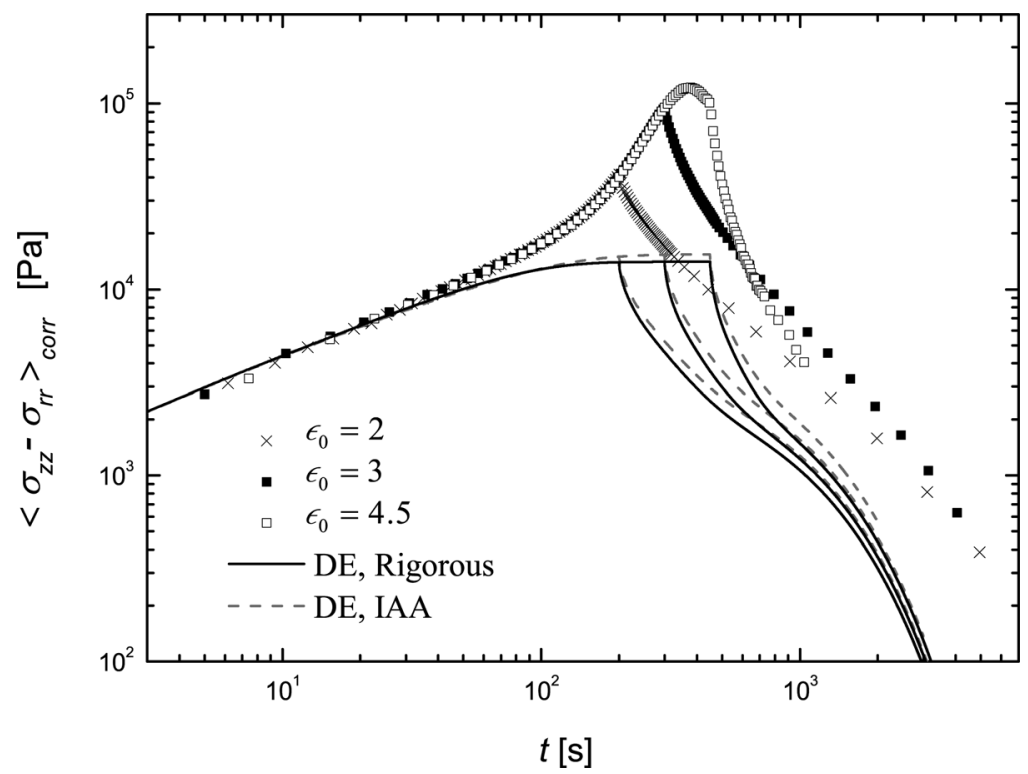

FIG. 10. The corrected extensional stress of Lupolen $1840 \mathrm{D}$ as a function of time at $130{ }^{\circ} \mathrm{C}$ with $\dot{\epsilon}_{0}^{+}=0.01 \mathrm{~s}^{-1}$ $(W i=5.2)$. The flow was stopped at an extension of $\epsilon_{0}=2,3$, and 4.5, respectively. The dashed and solid lines are the corresponding DE predictions with and without IAA, respectively. 


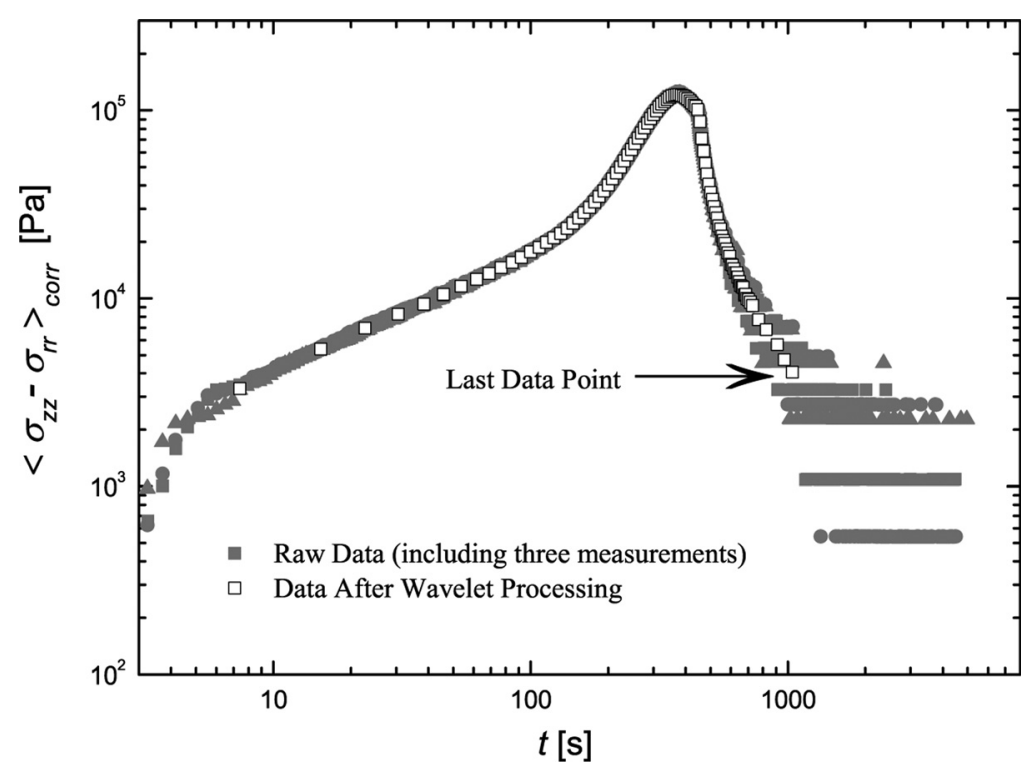

FIG. 11. Comparison of the raw data and the data after wave processing for Lupolen $1840 \mathrm{D}\left(\dot{\epsilon}_{0}^{+}=0.01 \mathrm{~s}^{-1}\right.$, $\left.\epsilon_{0}=4.5\right)$ at $130^{\circ} \mathrm{C}$.

we refer to Eq. (5) as the DE model, this relates to the nonlinear properties of the equation. $\mathbf{S}_{\mathrm{DE}}$ is the relative strain. The rigorous form and the independent alignment approximation (IAA) of $\mathbf{S}_{\mathrm{DE}}$ are given by Eqs. (7) and (8), respectively

$$
\begin{aligned}
& \mathbf{S}_{\mathrm{DE}}^{\mathrm{Rigorous}}\left(t, t^{\prime}\right)=\frac{15}{4} \frac{1}{\langle|\mathrm{E} \cdot \mathbf{u}|\rangle}\left\langle\frac{\mathrm{E} \cdot \mathbf{u} \mathrm{E} \cdot \mathbf{u}}{|\mathrm{E} \cdot \mathbf{u}|}\right\rangle \\
& \mathrm{S}_{\mathrm{DE}}^{\mathrm{IAA}}\left(t, t^{\prime}\right)=5\left\langle\frac{\mathrm{E} \cdot \mathbf{u} \mathrm{E} \cdot \mathbf{u}}{|\mathrm{E} \cdot \mathbf{u}|^{2}}\right\rangle=5 \mathrm{~S}\left(t, t^{\prime}\right) .
\end{aligned}
$$

In both equations, $\mathbf{u}$ is the unit vector and $\mathbf{E}$ the relative deformation gradient tensor. The bracket denotes an average over an isotropic distribution and the analytical formulas can be found in Urakawa et al. (1995) for uniaxial and biaxial deformations. K-BKZ representations [Bird et al. (1987)] that closely approximate the DE model with and without IAA for general deformations have been provided by Currie (1982) and Hassager and Hansen (2010), respectively. It appears from Figs. 9 and 10 that the IAA closely approximates the rigorous model in this situation.

A significantly different flow behavior is observed in the stress relaxation performed before $\left(\epsilon_{0}=2\right.$ and 3$)$ and after the overshoot $\left(\epsilon_{0}=4.5\right)$. The measured stress decays much faster after the overshoot for both melts. Similarly to linear NMMD polymer melts [Nielsen et al. (2008)], the elongational stress seems to decay nearly toward a DE based stress at large times after the overshoot has been passed. At smaller imposed strains, the stress of the branched LDPE melts (in Figs. 9 and 10) remains considerably larger than the DE prediction. This is similar to the observations in Rasmussen et al. (2009) for a branched NMMD polystyrene melt.

We also analyzed the stress decay by fitting the data with a sum of exponentially decaying modes as 


$$
\frac{\sigma^{-}(t)}{\sigma^{-}(0)}=\sum_{i} A_{i} \exp \left(-t / \tilde{\tau}_{i}\right)
$$

where $\sigma^{-}(0)$ is the stress when the flow is stopped in Figs. 9 and 10. Figure 12 shows the average relaxation time $\tilde{\tau}_{0}$ as a function of the imposed Hencky strain. Here, the average relaxation time is defined as $\tilde{\tau}_{0}=\sum_{i} A_{i} \tilde{\tau}_{i} / \sum_{i} A_{i}$. Both melts show that in extensional stress decay, the average relaxation time decreases with higher imposed Hencky strain. The average relaxation times $\tau_{0}$ for small Hencky strain defined in Eq. (1) have been included in the figure for reference.

\section{REVERSED FLOW}

In Figs. 13 and 14, we show the measured extensional stress as a function of Hencky strain for the reversed biaxial flow on Lupolen 3020D and Lupolen 1840D, respectively, at $130{ }^{\circ} \mathrm{C}$. In the figures, only the plots which are reversed at $\epsilon_{0} \geq 4.5$ were duplicated and represent the de-noised data after the wavelet treatments. We did not repeat the measurements which were reversed at Hencky strain lower than 4.5. For these measurements, we simply picked one data point from every ten points in the original experimental data set and thus the corresponding plots show the data without noise reduction. The solid lines in the figures show the rigorous DE predictions.

Different behavior in the reversed extensional flow has been observed, before and after the overshoot as well. Before the overshoot, the experimental observations depart increasingly from the DE predictions with increasing imposed maximal strain $\left(\epsilon_{0}\right)$. However, when the flow is reversed at even higher Hencky strain (after the overshoot), the deviations seem to reduce. In Fig. 15, we show the measured strain recovery $\epsilon_{R}$ as a function of Hencky strain $\epsilon_{0}$ for Lupolen 3020D and 1840D. It can be seen more clearly that

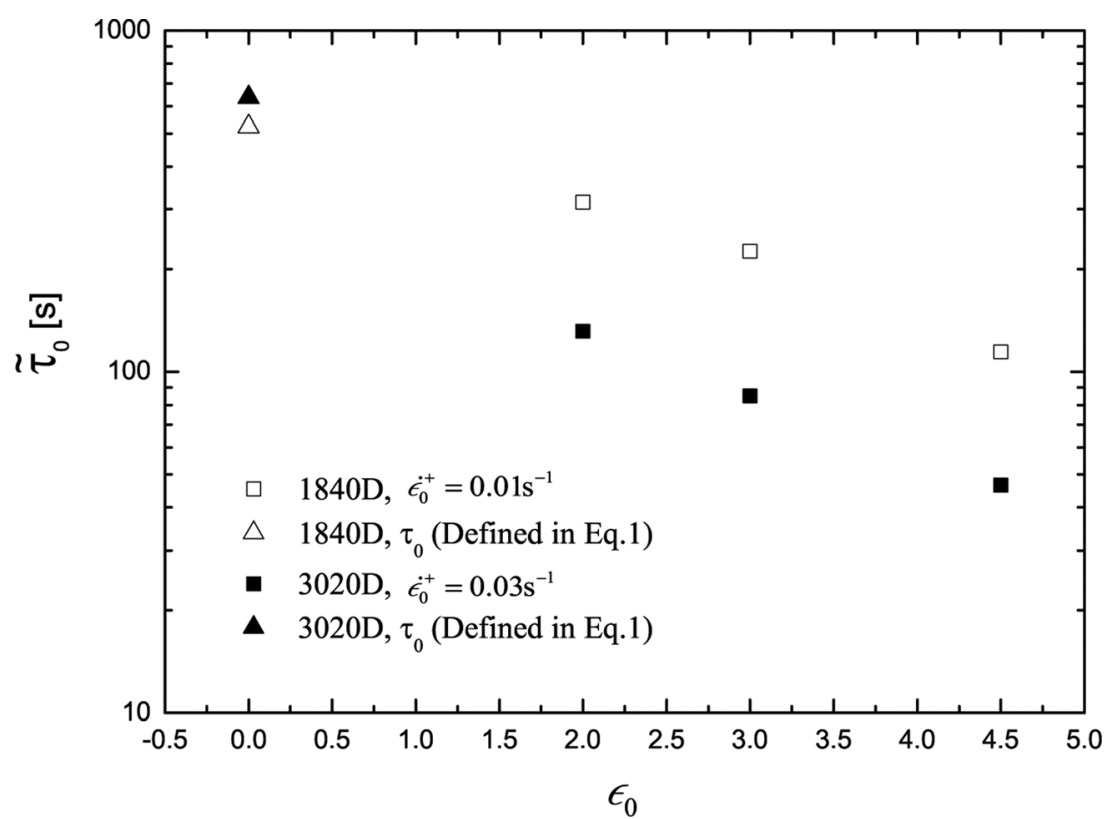

FIG. 12. The average relaxation time in extensional stress decay of Lupolen 3020D and 1840D as a function of Hencky strain at $130^{\circ} \mathrm{C}$. 


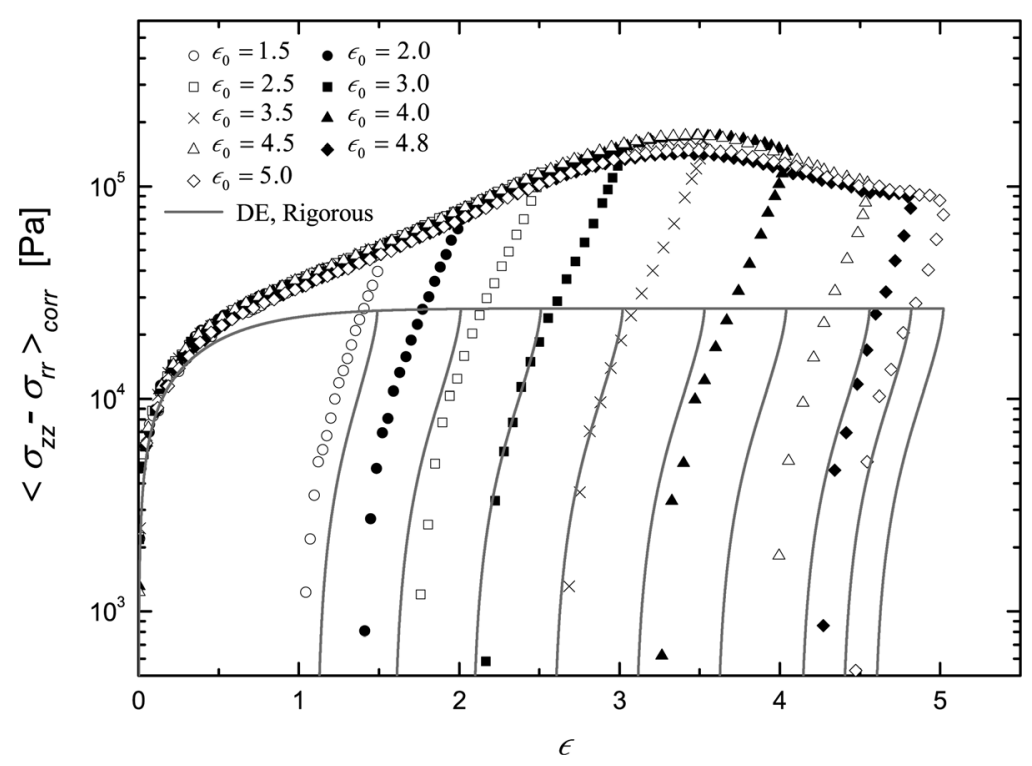

FIG. 13. The corrected startup and reversed stress of Lupolen $3020 \mathrm{D}$ at $130^{\circ} \mathrm{C}$ as a function of Hencky strain. The startup of the flow was uniaxial elongation with $\dot{\epsilon}_{0}^{+}=0.03 \mathrm{~s}^{-1}(W i=19.1)$. The flow was reversed at $\epsilon_{0}=1.5,2,2.5,3,3.5,4,4.5,4.8$, and 5.0, respectively, with the identical strain rate $\dot{\epsilon}_{0}^{-}=0.03 \mathrm{~s}^{-1}$. The solid lines are the corresponding rigorous DE predictions.

before the overshoot the strain recovery increases, while after the overshoot it decreases, which indicates that the melt becomes less elastic.

In order to investigate further the strain recovery, we made more measurements for Lupolen 3020D with different strain rates $\dot{\epsilon}_{0}^{+}$in the startup and the corresponding $\dot{\epsilon}_{0}^{-}=\dot{\epsilon}_{0}^{+}$

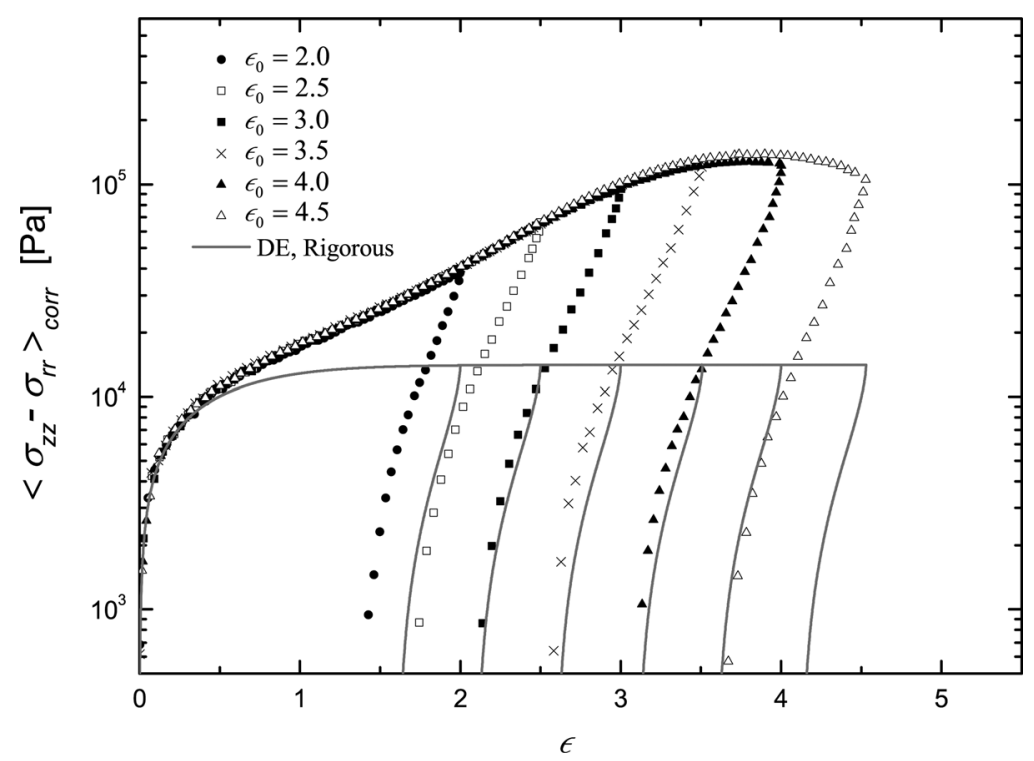

FIG. 14. The corrected startup and reversed stress of Lupolen $1840 \mathrm{D}$ at $130^{\circ} \mathrm{C}$ as a function of Hencky strain. The startup of the flow was uniaxial elongation with $\dot{\epsilon}_{0}^{+}=0.01 \mathrm{~s}^{-1}(W i=5.2)$. The flow was reversed at $\epsilon_{0}=2,2.5,3,3.5,4$, and 4.5 , respectively, with the identical strain rate $\dot{\epsilon}_{0}^{-}=0.01 \mathrm{~s}^{-1}$. The solid lines are the corresponding rigorous DE predictions. 


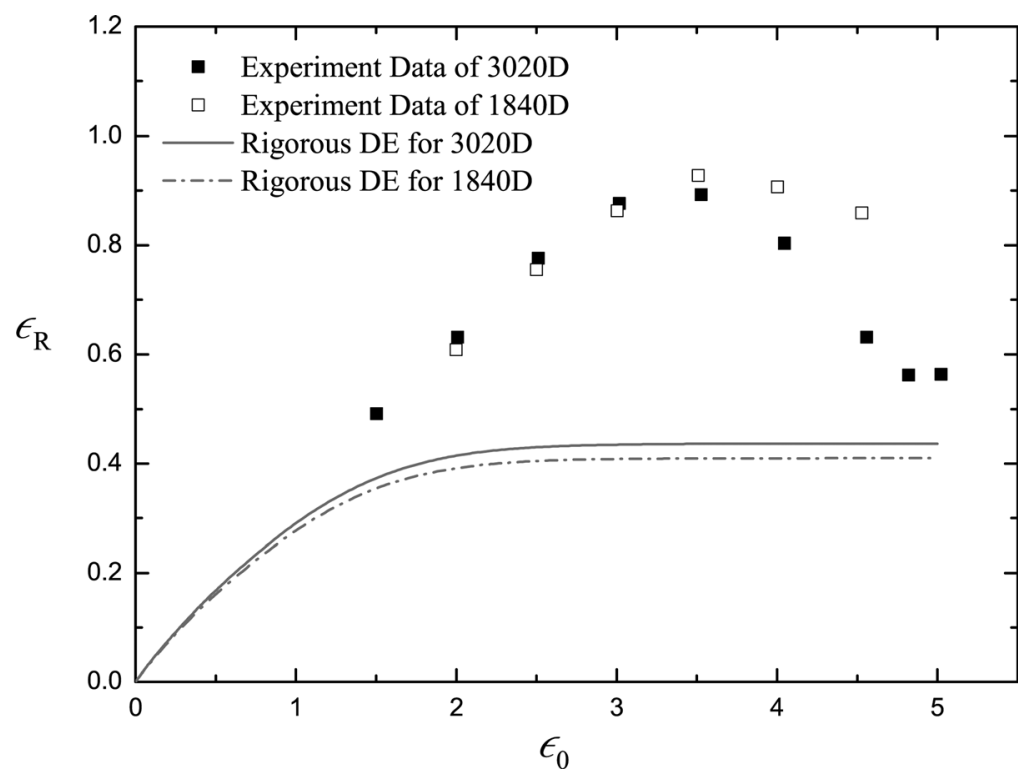

FIG. 15. The strain recovery as a function of Hencky strain for Lupolen 3020D $\left(\dot{\epsilon}_{0}^{+}=\dot{\epsilon}_{0}^{-}=0.03 \mathrm{~s}^{-1}\right.$, $W i=19.1)$ and $1840 \mathrm{D}\left(\dot{\epsilon}_{0}^{+}=\dot{\epsilon}_{0}^{-}=0.01 \mathrm{~s}^{-1}, W i=5.2\right)$ at $130^{\circ} \mathrm{C}$. The lines are the rigorous DE predictions.

in the reversed flow. Figure 16 shows the experimental results and the DE predictions. Before the overshoot, the strain recovery $\epsilon_{R}$ increases with higher Hencky strain $\epsilon_{0}$ and higher strain rate $\dot{\epsilon}_{0}^{+}$, and all the values are higher than the DE predictions. This is likely to be the result of chain stretch not presented in the DE model. But after the overshoot, $\epsilon_{R}$ decreases with $\epsilon_{0}$ and $\dot{\epsilon}_{0}^{+}$. This may indicate that there is less chain stretch after the

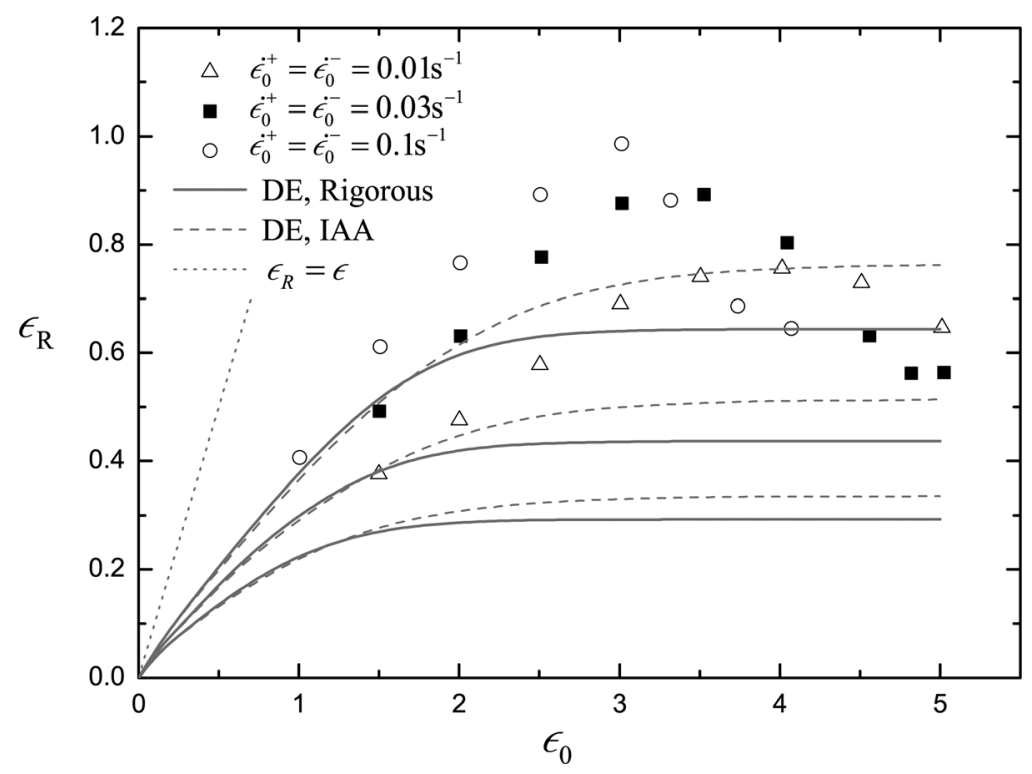

FIG. 16. The strain recovery as a function of Hencky strain for Lupolen $3020 \mathrm{D}$ at $130^{\circ} \mathrm{C}$ with different strain rates $\dot{\epsilon}_{0}^{+}=\dot{\epsilon}_{0}^{-}=0.01,0.03,0.1 \mathrm{~s}^{-1}(W i=6.4,19.1,63.7)$. The dashed and solid lines are the corresponding DE predictions with and without IAA, respectively. 
maximum. The experimental data on $\dot{\epsilon}_{0}^{+}=0.03 \mathrm{~s}^{-1}$ also show that the strain recovery $\epsilon_{R}$ tends to reach a constant value for large strains. This observation, however, is based on limited data. Furthermore, here the rigorous DE predictions show observable differences from the DE with IAA. Indeed, it is expected that the IAA will lead to significant deviations from the rigorous model in reversed flow [Doi (1980)].

\section{DISCUSSION}

Both the measurements of stress relaxation and reversed flow indicate that the branched LDPE melts show a similarity to linear polymers after the overshoot, since the experimental data recover to the DE predictions. However, the DE model cannot predict the strain hardening effect of the highly branched LDPE melts. There is a significant deviation between the measured data and the predicted behavior in the start-up. It is necessary to take other effects than pure configurational stress into account.

While a clear understanding of the molecular phenomena involved in the stress overshoot does not seem available presently, we wish to compare the experimental observations of Lupolen 3020D with the predictions from two of the commonly used constitutive theories: The pom-pom model and the interchain pressure model. Since the Lupolen 3020D melt is highly polydisperse, we will use a multi mode version for each model.

The pom-pom model was originally proposed by McLeish and Larson (1998) with both an integral and a differential form. A multi mode version of the pom-pom model was proposed by Inkson et al. (1999) for various LDPE melts. Blackwell et al. (2000) improved the multi mode pom-pom fit by smoothing the sharp transitions of the model. Subsequently, an extended pom-pom (XPP) model was proposed by Verbeeten et al. (2001) to overcome several drawbacks of the original pom-pom model, and more recently the XPP model was used by Oishi et al. (2011) to simulate viscoelastic free surface flows.

Since the pom-pom model has not been used to predict stress relaxation and reversed flow following uniaxial extension, here we compare our experimental data with the multi mode version of the original pom-pom model. The stress tensor of the differential approximation of a multi mode pom-pom model is expressed as [Inkson et al. (1999)]

$$
\sigma=\sum_{i=1}^{n} \sigma_{i}=\sum_{i=1}^{n} g_{i} \lambda_{i}^{2}(t) \mathbf{S}_{\mathrm{PP}, i}(t),
$$

where $\mathbf{S}_{\mathrm{PP}, i}$ represents the evolution of orientation and $\lambda_{i}$ [Blackwell et al. (2000)] represents the evolution of backbone stretch for each mode $i$ given by

$$
\begin{gathered}
\mathbf{S}_{\mathrm{PP}, i}=\frac{3 \mathbf{A}_{i}}{\operatorname{trace}\left(\mathbf{A}_{i}\right)}, \\
\frac{\partial}{\partial t} \mathbf{A}_{i}=\boldsymbol{\kappa} \cdot \mathbf{A}_{i}+\mathbf{A}_{i} \cdot \boldsymbol{\kappa}^{T}-\frac{1}{\tau_{i}}\left(\mathbf{A}_{i}-\mathbf{I}\right), \\
\frac{\partial}{\partial t} \lambda_{i}=\lambda_{i}\left(\boldsymbol{\kappa}: \mathbf{S}_{\mathrm{PP}, i}\right)-\frac{1}{\tau_{s, i}}\left(\lambda_{i}-1\right) e^{\nu_{i}\left(\lambda_{i}-1\right)},
\end{gathered}
$$

with the initial conditions $\mathbf{A}_{i}(-\infty)=\mathbf{I}$ and $\lambda_{i}(-\infty)=1 . \boldsymbol{\kappa}$ is the transpose of the velocity gradient $\left(\kappa_{i j}=\partial v_{i} / \partial x_{j}\right), \tau_{s, i}$ is the relaxation time for stretch, $\nu_{i}=2 /\left(q_{i}-1\right)$ 
[McLeish (2002)], and $q_{i}$ is the number of arms on each branch point of the pom-pom polymer. There are four fitting parameters in the pom-pom equations for each mode $i: g_{i}$, $\tau_{i}, \tau_{s, i}$, and $q_{i}$. The linear viscoelastic parameters $g_{i}$ and $\tau_{i}$ are directly obtained from the relaxation spectrum in Table I. The values of $\tau_{s, i}$ and $q_{i}$ associated with the nonlinear properties are adjusted by "trial and error." In the reversed flow, when $\lambda_{i}<1$, there is a modification for the parameter $\tau_{i}$ given by [Lee et al. (2001)]

$$
\frac{1}{\tau_{i}^{*}}=\left\{\begin{array}{c}
\frac{1}{\tau_{i}} \quad \text { for } 1 \leq \lambda_{i} \leq q_{i} \\
\frac{1}{\tau_{i}}+\frac{1}{\lambda_{i}} \frac{\partial \lambda_{i}}{\partial t}-\boldsymbol{\kappa}: \mathbf{S}_{\mathrm{PP}, i} \quad \text { for } \lambda_{i}<1
\end{array}\right.
$$

The interchain pressure concept was originally proposed by Marrucci and Ianniruberto (2004). The stress tensor of the interchain pressure model developed initially for linear monodisperse melts [Wagner et al. (2005)] is given by the integral

$$
\sigma(t)=\int_{-\infty}^{t} M\left(t-t^{\prime}\right) f^{2}\left(t, t^{\prime}\right) 5 \mathbf{S}\left(t, t^{\prime}\right) \mathrm{d} t^{\prime},
$$

where $f$ represents the evolution of the tension in a chain segment given by

$$
\frac{\partial}{\partial t} f=f\left[(\boldsymbol{\kappa}: \mathbf{S})-\frac{f\left(f^{3}-1\right)}{\tau_{a}}\right],
$$

with the initial condition $f\left(t^{\prime}, t^{\prime}\right)=1 . \tau_{a}$ is the tube diameter relaxation time. For the highly polydisperse LDPE melt, we use a multi mode version in the form

$$
\begin{gathered}
\sigma(t)=\sum_{i} \int_{-\infty}^{t} \frac{g_{i}}{\tau_{i}} e^{-\left(t-t^{\prime}\right) / \tau_{i}} f_{i}^{2}\left(t, t^{\prime}\right) 5 \mathbf{S}\left(t, t^{\prime}\right) \mathrm{d} t^{\prime} \\
\frac{\partial}{\partial t} f_{i}=f_{i}\left[(\boldsymbol{\kappa}: \mathbf{S})-\frac{f_{i}\left(f_{i}^{3}-1\right)}{\tau_{a, i}}\right]
\end{gathered}
$$

with three fitting parameters for each mode $i: g_{i}, \tau_{i}$, and $\tau_{a, i}$. The values of $g_{i}$ and $\tau_{i}$ are the same with the ones in the pom-pom equations. The values of $\tau_{a, i}$ are again adjusted by "trial and error."

Table II shows the fitting parameters used in the multi mode pom-pom model and the multi mode interchain pressure model for Lupolen 3020D. Figure 17 compares the predicted extensional stress growth coefficient at different strain rates with the experimental data. Neither of the two models can predict the overshoot. But they both approximately fit the startup of the measurements before the overshoot at different strain rates. Wagner and Rolón-Garrido (2008) proposed a modified interchain pressure model which captures the overshoot for a pom-pom polystyrene. We did not consider this model here, because in stress relaxation $(\dot{\epsilon}=0)$ the tube diameter relaxation time $\tau_{a}$ in the modified model goes to infinity, and the interchain pressure effect vanishes in the evolution equation.

Figure 18 compares the predictions of stress relaxation of the two models with the experimental results from Fig. 9. Both models seem to describe the stress data in the relaxation phase when the relaxation is initiated at $\epsilon_{0}=2$ and 3 , that is, before the stress maximum is reached. However, the models do not capture the rapid stress decay during the relaxation which is initiated after the stress maximum $\left(\epsilon_{0}=4.5\right)$. In addition, the 
TABLE II. Fitting parameters used in the multi mode pom-pom model and the multi mode interchain pressure model for the Lupolen $3020 \mathrm{D}$ melt at $130^{\circ} \mathrm{C}$.

\begin{tabular}{|c|c|c|c|c|c|}
\hline \multirow[b]{2}{*}{ Mode $i$} & \multicolumn{2}{|c|}{ Relaxation spectrum } & \multicolumn{2}{|c|}{ Pom-pom } & \multirow{2}{*}{$\frac{\text { Interchain pressure }}{\tau_{a, i}(\mathrm{~s})}$} \\
\hline & $\tau_{i}(\mathrm{~s})$ & $g_{i}(\mathrm{~Pa})$ & $q_{i}$ & $\tau_{s, i}(\mathrm{~s})$ & \\
\hline 1 & 0.009421 & 140281.5 & 2 & 0.001713 & 50 \\
\hline 2 & 0.061312 & 53547.1 & 2 & 0.011354 & 50 \\
\hline 3 & 0.319808 & 33532.91 & 2 & 0.061502 & 50 \\
\hline 4 & 1.8272 & 20196.16 & 2 & 0.358275 & 50 \\
\hline 5 & 10.4064 & 9170.150 & 3 & 2.08128 & 50 \\
\hline 6 & 57.9328 & 3551.614 & 4 & 12.8740 & 400 \\
\hline 7 & 329.024 & 983.4258 & 6 & 131.610 & 10000 \\
\hline 8 & 2097.92 & 101.618 & 6 & 2097.92 & 200000 \\
\hline
\end{tabular}

pom-pom model exhibits an oscillatory behavior not present in the data. This may be due to the differential formulation that constitutes an approximation of the pom-pom integral constitutive equation.

In Fig. 19, we compare our data for strain recovery $\left(\dot{\epsilon}_{0}^{+}=\dot{\epsilon}_{0}^{-}=0.03 \mathrm{~s}^{-1}\right.$, Fig. 16) with predictions of the DE model, the pom-pom model, and the interchain pressure model. None of the models capture the qualitative feature of a maximum in recoverable strain. The interchain pressure model gives a better prediction up to the recovery maximum corresponding in strain more or less to the strain for the stress maximum. The DE model interestingly gives the best prediction for the material stretched well beyond the stress maximum. While this may be fortuitous, it may also be interpreted as evidence that the branching structure plays very little role in the dynamics after the stress maximum.

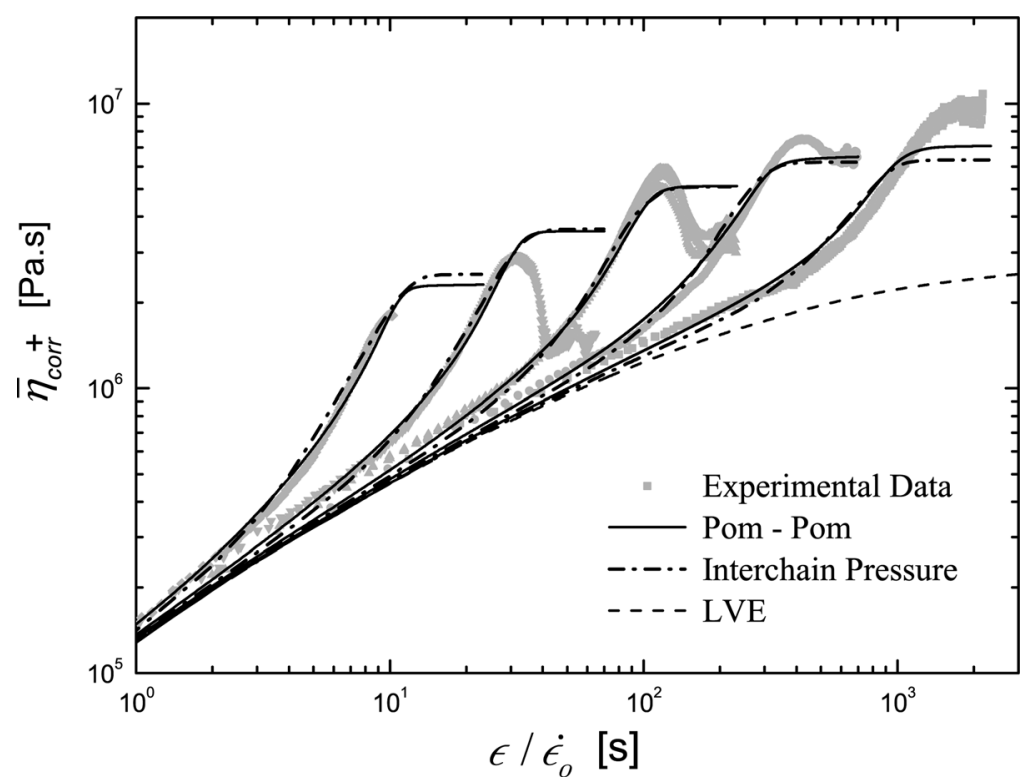

FIG. 17. Comparison of the measured extensional stress growth coefficient $\bar{\eta}_{c o r r}^{+}=\left\langle\sigma_{z z}-\sigma_{r r}\right\rangle_{\text {corr }} / \dot{\epsilon}_{0}$ for Lupolen $3020 \mathrm{D}$ with the pom-pom model, the interchain pressure model and the linear viscoelastic (LVE) prediction, at strain rates (from right to left) $\dot{\epsilon}_{0}=0.003,0.01,0.03,0.1,0.3 \mathrm{~s}^{-1}(W i=1.9,6.4,19.1,63.7,191.0)$ at $130^{\circ} \mathrm{C}$. The fitting parameters are listed in Table II. The experimental data are obtained from Rasmussen et al. (2005). 


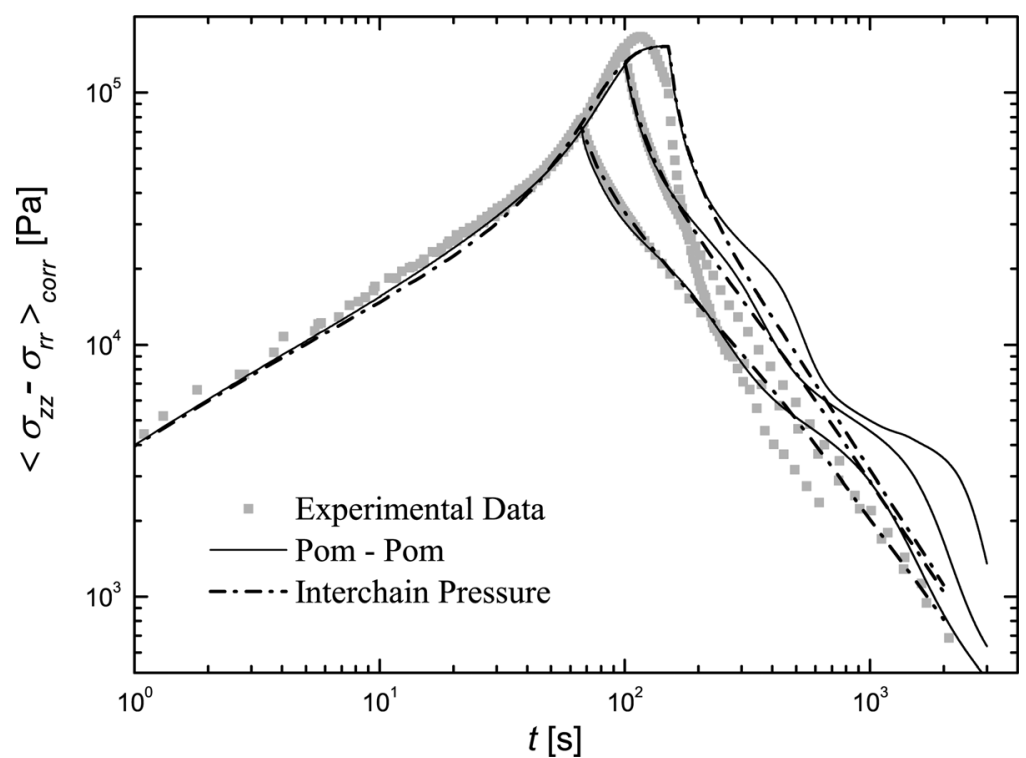

FIG. 18. Comparison of the measured stress relaxation for Lupolen $3020 \mathrm{D}$ at $130^{\circ} \mathrm{C}$ with the pom-pom model and the interchain pressure model, at strain rate $\dot{\epsilon}_{0}^{+}=0.03 \mathrm{~s}^{-1}(W i=19.1)$ in the startup. The fitting parameters are listed in Table II.

Finally as shown in Fig. 20, the prediction of the strain recovery from the interchain pressure model can fit the data before the overshoot quantitatively for several different strain rates in the startup. This is similar to the observations for the pom-pom polystyrene melt data [Rasmussen et al. (2009)].

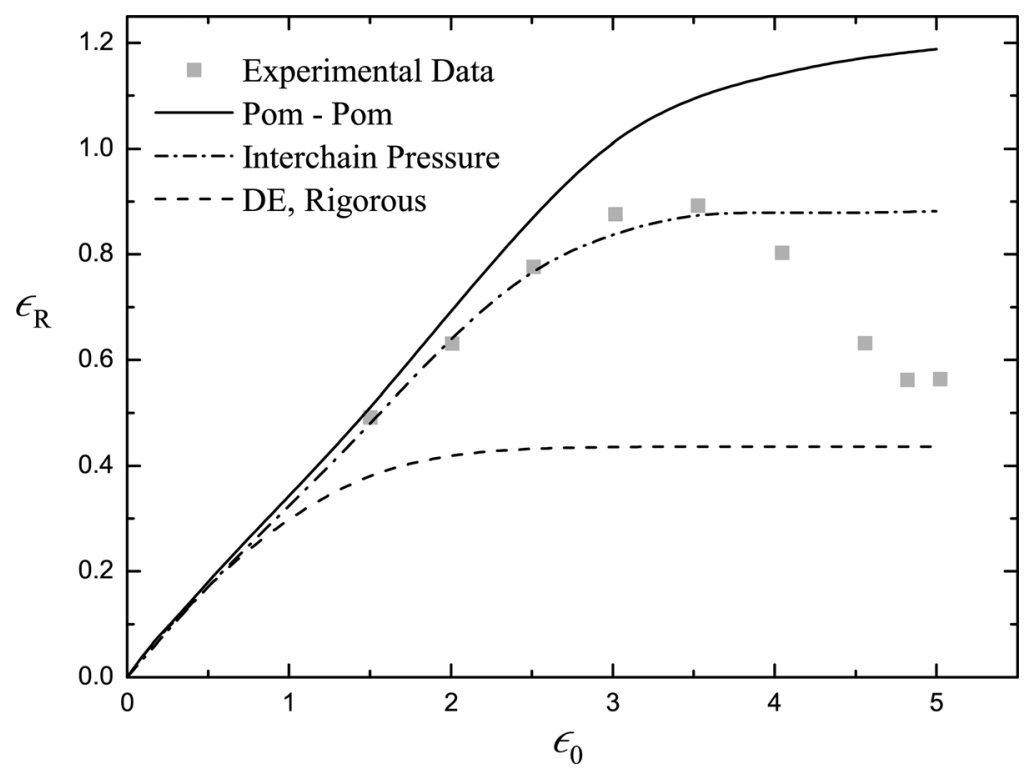

FIG. 19. Comparison of the measured strain recovery for Lupolen $3020 \mathrm{D}$ with the pom-pom model, the interchain pressure model, and the rigorous $\mathrm{DE}$ model at $130^{\circ} \mathrm{C}$ at strain rate $\dot{\epsilon}_{0}^{+}=\dot{\epsilon}_{0}^{-}=0.03 \mathrm{~s}^{-1}(\mathrm{Wi}=19.1)$. The fitting parameters are listed in Table II. 


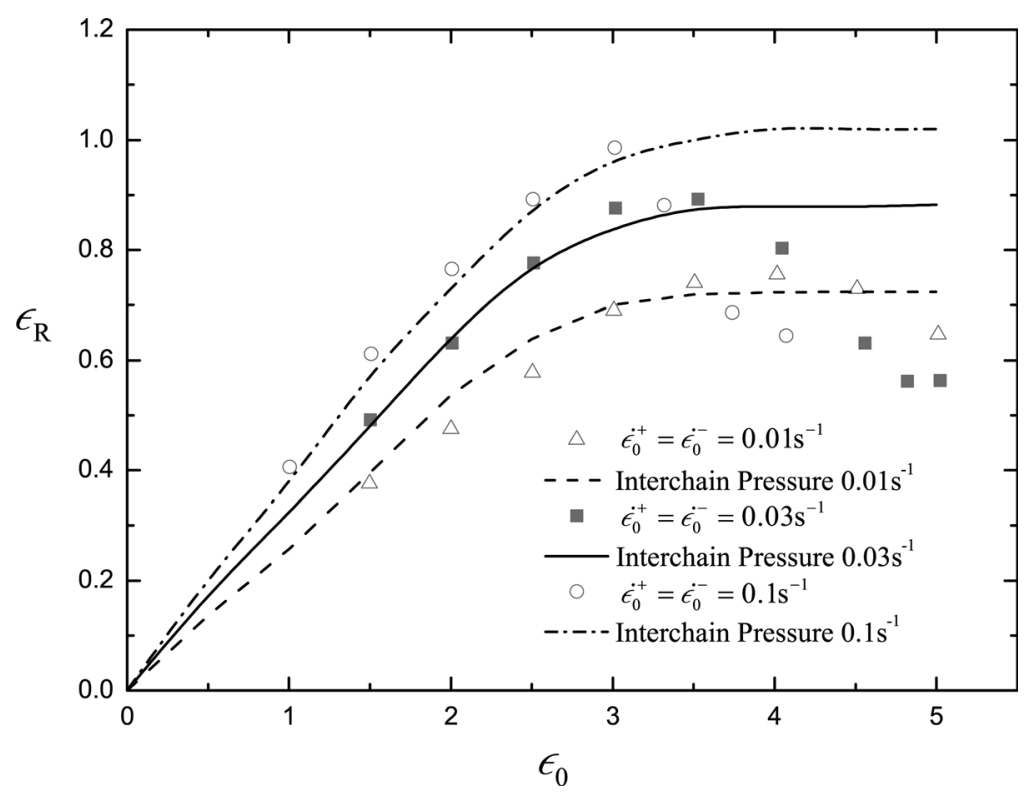

FIG. 20. Comparison of the measured strain recovery with the multi mode interchain pressure prediction for Lupolen $3020 \mathrm{D}$ at $130^{\circ} \mathrm{C}$ at different strain rates $\dot{\epsilon}_{0}^{+}=\dot{\epsilon}_{0}^{-}=0.01,0.03,0.1 \mathrm{~s}^{-1}(W i=6.4,19.1,63.7)$. The fitting parameters are listed in Table II.

\section{CONCLUSION}

We have measured stress relaxation and reversed biaxial flow, both following uniaxial extension, on Lupolen 3020D and Lupolen 1840D LDPE melts using an FSR. These branched polymers show stress overshoots followed by steady stress in uniaxial extension as previously reported by Rasmussen et al. (2005). After the overshoot, the stress relaxation measurements show a remarkably faster decrease in the transient stress compared with the measurements before the overshoot. In reversed flow, the strain recovery increases with the applied total Hencky strain until the strain at which the maximum in the stress is observed. After the overshoot, the strain recovery decreases with total applied Hencky strain, and it saturates at high strain values. Overall these measurements show that the melts become less elastic after the stress maximum.

Both the measurements of stress relaxation and reversed flow indicate that the branched LDPE melts behave similarly to linear polymers after the overshoot, since the experimental data recover to the DE predictions. Both the multi mode pom-pom model and the multi mode interchain pressure model can quantitatively predict the start-up of the uniaxial elongation before the overshoot. Neither model is able to capture even qualitatively the stress relaxation or strain recovery of the material exhibited after the overshoot. Clearly the dynamics involved in the stress overshoot exhibited by branched polymers still needs new theoretical insight.

\section{ACKNOWLEDGMENT}

The authors thank the European Union Seventh Framework Programme for financial support under the Marie Curie Initial Training Network DYNACOP (Grant Agreement No.: 214627). 


\section{References}

Bach, A., H. K. Rasmussen, and O. Hassager, "Extensional viscosity for polymer melts measured in the filament stretching rheometer," J. Rheol. 47(2), 429-441 (2003).

Bastian, H., "Non-linear viscoelasticity of linear and long-chain-branched polymer melts in shear and extensional flows," Ph.D. thesis, Institut fulr Kunststofftechnologie der Universität Stuttgart, 2001.

Bejenariu, A. G., H. K. Rasmussen, A. L. Skov, O. Hassager, and S. M. Frankaer, "Large amplitude oscillatory extension of soft polymeric networks," Rheol. Acta 49, 807-814 (2010).

Bird, R. B., R. C. Armstrong, and O. Hassager, Dynamics of Polymeric Liquids (Wiley, New York, 1987), Vol. 1, pp. 436.

Blackwell, R. J., T. C. B. McLeish, and O. G. Harlen, "Molecular drag-strain coupling in branched polymer melts," J. Rheol. 44(1), 121-136 (2000).

Burghelea, T. I., Z. Starý, and H. Münstedt, "On the 'viscosity overshoot' during the uniaxial extension of a low density polyethylene,” J. Non-Newtonian Fluid Mech. 166, 1198-1209 (2011).

Currie, P. K., "Constitutive equations for polymer melts predicted by the Doi-Edwards and Curtiss-Bird kinetic theory models," J. Non-Newtonian Fluid Mech. 11, 53-68 (1982).

Doi, M., "Stress relaxation of polymeric liquids after double-step strain," J. Polym. Sci.: Polym. Phys. Ed. 18, 1891-1905 (1980).

Doi, M., and S. F. Edwards, "Dynamics of concentrated polymer systems. VI. Rheological properties," J. Chem. Soc., Faraday Trans. 1 75, 38-54 (1979).

Hassager, O., and R. Hansen, "Constitutive equations for the Doi-Edwards model without independent alignment," Rheol. Acta 49, 555-562 (2010).

Inkson, N. J., T. C. B. McLeish, O. G. Harlen, and D. J. Groves, "Predicting low density polyethylene melt rheology in elongational and shear flows with 'pom-pom' constitutive equations," J. Rheol. 43, 873-895 (1999).

Kolte, M. I., H. K. Rasmussen, and O. Hassager, "Transient filament stretching rheometer II: Numerical simulation," Rheol. Acta 36, 285-302 (1997).

Lee, K., M. R. Mackley, T. C. B. McLeish, T. M. Nicholson, and O. G. Harlen, "Experimental observation and numerical simulation of transient 'stress fangs' within flowing molten polyethylene," J. Rheol. 45(6), 1261-1277 (2001).

Lyhne, A., H. K. Rasmussen, and O. Hassager, "Simulation of elastic rupture in extension of entangled monodisperse polymer melts,” Phys. Rev. Lett. 102, 138301 (2009).

Mallat, S. G., A Wavelet Tour of Signal Processing (Academic, London, 2009), pp. 220-303.

Marrucci, G., and G. Ianniruberto, "Interchain pressure effect in extensional flows of entangled polymer melts," Macromolecules 37, 3934-3942 (2004).

McKinley, G. H., and T. Sridhar, "Filament-stretching rheometry of complex fluids," Annu. Rev. Fluid Mech. 34, 375-415 (2002).

McLeish, T. C. B., "Tube theory of entangled polymer dynamics," Adv. Phys. 51(6), 1379-1527 (2002).

McLeish, T. C. B., and R. G. Larson, "Molecular constitutive equations for a class of branched polymers: The pom-pom polymer," J. Rheol. 42(1), 81-110 (1998).

Meissner, J., "Dehnungsverhalten von polyäthylen-schmelzen,” Rheol. Acta 10, 230-242 (1971).

Meissner, J., "Development of a universal extensional rheometer for the uniaxial extension of polymer melts," Transactions of the society of Rheology 16(3), 405-420 (1972).

Meissner, J., and J. Hostettler, "A new elongational rheometer for polymer melts and other highly viscoelastic liquids," Rheol. Acta 33, 1-21 (1994).

Münstedt, H., "New universal extensional rheometer for polymer melts, measurements on a polystyrene sample," J. Rheol. 23, 421-436 (1979).

Nielsen, J. K., and H. K. Rasmussen, "Reversed extension flow," J. Non-Newtonian Fluid Mech. 155, 15-19 (2008).

Nielsen, J. K., H. K. Rasmussen, and O. Hassager, "Stress relaxation of narrow molar mass distribution polystyrene following uniaxial extension,” J. Rheol. 52(4), 885-899 (2008).

Nordmaier, E., U. Lanver, and M. D. Lechner, "The molecular structure of low-density polyethylene 1. Longchain branching and solution properties," Macromolecules 23, 1072-1076 (1990a). 
Nordmaier, E., U. Lanver, and M. D. Lechner, “The molecular structure of low-density polyethylene 2. Particle scattering factors," Macromolecules 23, 1077-1084 (1990b).

Oishi, C. M., F. P. Martins, M. F. Tomé, J. A. Cuminato, and S. McKee, "Numerical solution of the eXtended Pom-Pom model for viscoelastic free surface flows," J. Non-Newtonian Fluid Mech. 166, 165-179 (2011).

Raible, T., A. Demarmels, and J. Meissner, "Stress and recovery maxima in LDPE melt elongation," Polym. Bull. 1, 397-402 (1979).

Rasmussen, H. K., A. G. Bejenariu, O. Hassager, and D. Auhl, "Experimental evaluation of the pure configurational stress assumption in the flow dynamics of entangled polymer melts," J. Rheol. 54(6), 1325-1336 (2010).

Rasmussen, H. K., A. L. Skov, J. K. Nielsen, and P. Laillé, "Elongational dynamics of multiarm polystyrene," J. Rheol. 53(2), 401-415 (2009).

Rasmussen, H. K., J. K. Nielsen, A. Bach, and O. Hassager, "Viscosity overshoot in the start-up of uniaxial elongation of low density polyethylene melts," J. Rheol. 49(2), 369-381 (2005).

Rasmussen, H. K., and O. Hassager, "Reply to: 'On the "viscosity overshoot" during the uniaxial extension of a low density polyethylene,”’ J. Non-Newtonian Fluid Mech. 106, 171-172 (2012).

Read, D. J., D. Auhl, C. Das, J. D. Doelder, M. Kapnistos, I. Vittorias, and T. C. B. McLeish, "Linking models of polymerization and dynamics to predict branched polymer structure and flow," Science 333, 1871-1874 (2011).

Sentmanat, M., "Miniature universal testing platform: From extensional melt rheology to solid-state deformation behaviour," Rheol. Acta 43, 657-669 (2004).

Sentmanat, M., B. N. Wang, and G. H. McKinley, "Measuring the transient extensional rheology of polyethylene melts using the SER universal testing platform," J. Rheol. 49, 585-606 (2005).

Szabo, P., "Transient filament stretching rheometer part I: Force balance analysis," Rheol. Acta 36, 277-284 (1997).

Urakawa, O., M. Takahashi, T. Masuda, and N. Golshan Ebrahimi, "Damping functions and chain relaxation in uniaxial and biaxial extensions: Comparison with the Doi-Edwards theory," Macromolecules 28, 7196-7201 (1995).

Verbeeten, W. M. H., G. W. M. Peters, and F. P. T. Baaijens, "Differential constitutive equations for polymer melts: The extended PomPom model," J. Rheol. 45(4), 823-843 (2001).

Wagner, M. H., S. Kheirandish, and O. Hassager, "Quantitative prediction of transient and steady-state elongational viscosity of nearly monodisperse polystyrene melts,” J. Rheol. 49(6), 1317-1327 (2005).

Wagner, M. H., and S. E. Stephenson, "The irreversibility assumption of network disentanglement inflowing polymermelts and its effects on elastic recoil predictions," J. Rheol. 23, 489-504 (1979).

Wagner, M. H., T. Raible, and J. Meissner, "Tensile stress overshoot in uniaxial extension of a LDPE melt," Rheol. Acta 18, 427-428 (1979).

Wagner, M. H., and V. H. Rolón-Garrido, "Verification of branch point withdrawal in elongational flow of pom-pom polystyrene melt,” J. Rheol. 52(5), 1049-1068 (2008).

Wang, Y., P. Boukany, S. Q. Wang, and X. Wang, "Elastic breakup in uniaxial extension of entangled polymer melts," Phys. Rev. Lett. 99, 237801 (2007). 